\title{
Exploring Mode Effects in a Panel Survey of New Businesses
}

\author{
Betsy Santos and David DesRoches \\ Mathematica Policy Research, Inc.
}

\begin{abstract}
Establishment surveys among the business population are often hampered by low response rates and high costs. In an effort to improve response rates and reduce costs, survey researchers have employed multi-mode data collection methods, often mixing a selfadministered visual mode (such as a mail or web survey) with an aural mode such as telephone. This method provides both the benefits of the selfadministered questionnaire (cost and convenience) and those of the more persuasive interviewer-administered mode for nonresponse follow-up. A better understanding of the potential effects of conducting multi-mode establishment surveys can provide information about the characteristics of businesses and respondents who choose the different modes and also guide future data collection efforts among this population. We used data from the baseline and three follow-up waves of the Kauffman Firm Survey (KFS), a longitudinal survey of new businesses offering a web survey to the entire sample followed by an opportunity for web nonresponders to complete their interviews by telephone, to shed light on the differences between businesses that complete the survey using the different modes and determine whether any mode effects can be detected. Specifically, we present a longitudinal analysis of three groups of KFS businesses: those that opted to complete all four rounds of the survey on the web; those that opted to complete all four rounds by telephone; and a group of "switchers" that completed two rounds by web and two rounds by telephone. For this descriptive analysis, we examine differences in these three groups across industry, size, and the complexity of the business, as well as differences in respondent demographics. We also analyze indicators of business growth, such as employment, assets, revenue, and profit or loss.
\end{abstract}

Keywords: business surveys, web surveys, mode choice

\section{Introduction}

Surveys among the business population, especially new businesses, are often hampered by low response rates and high costs. To address this issue, researchers have begun offering alternative response modes to reduce respondent burden, which has shown to improve response rates in business surveys
(Willimack, Nichols, and Sudman 2002). These alternate response modes often include mixing a selfadministered visual mode (such as a mail or web survey) with an aural mode such as telephone. A mixed-mode design is believed to accommodate personal preferences, which will lead to nonresponse reduction (Dillman and Tarnai 1988), and including a web component in a mixed-mode survey has been used as a strategy for containing costs compared to traditional mail surveys (Couper 2000; Schaefer and Dillman 1998). Although some research has explored survey mode preference among business populations (Tarnai and Paxson 2004), mode preference among businesses has not been studied extensively from a longitudinal perspective. Information about the modes in which respondents complete surveys across several years provides a more comprehensive understanding of the types of businesses that are likely to respond to a web survey. This information will help survey researchers design more effective and persuasive advance materials to maximize web participation in surveys, including longitudinal surveys, and will enable them to target potential participants more effectively.

\section{Methods}

The data for this research come from the Kauffman Firm Survey, sponsored by the Ewing Marion Kauffman Foundation. The KFS is a longitudinal panel study of new businesses (businesses that started operations in 2004) using the Dun \& Bradstreet database as the sample frame.

The KFS baseline survey was conducted with the principals of 4,928 businesses over a 12-month period from July 2005 through July 2006. To date, three annual follow-up surveys have been conducted with businesses still in existence. For the baseline survey, businesses were sent an advance mailing that contained login and password information for logging into the KFS web survey. In order to maximize the number of initial participants accessing the web, computerassisted telephone interviewing (CATI) follow-up was not mentioned. Reminder postcards were sent a week later to nonresponders. Businesses that did not complete the survey by web after these attempts were contacted by telephone to complete it via CATI. 
At the end of the baseline interview, we collected email addresses for respondents. For those respondents who provided a valid email address, we used email first to attempt to contact them for the three follow-up interviews. All efforts were made to interview the same business owner who completed the interview in the previous round. The advance email, like the advance mailing, contained login information for completing the interview on the web, with no mention of CATI follow-up, and it contained a direct link to the survey website, which prefilled the login and password. Subsequent contact attempts for nonresponders included a reminder email, advance letter mailing, and reminder postcard before the business was contacted by telephone. As Table 1 shows, the use of email contacts increased the percentage of businesses completing by web considerably in the First Follow-Up. The percentage of businesses completing by web increased in the Second and Third Follow-Ups as well.

Table 1. At Each Follow-Up Round of KFS Data Collection, a Greater Proportion Respond by Web (Row Percentages)

\begin{tabular}{lcc}
\hline Survey & Web & CATI \\
\hline Baseline $(\mathrm{n}=4,928)$ & 23 & 77 \\
First Follow-Up $(\mathrm{n}=3,998)$ & 59 & 41 \\
Second Follow-Up $(\mathrm{n}=3,392)$ & 63 & 37 \\
Third Follow-Up $(\mathrm{n}=2,915)$ & 65 & 35 \\
\hline
\end{tabular}

For the purposes of this paper, only businesses that completed all four rounds of the survey were included in the analysis. Specifically, we looked at three groups: those that completed all four rounds of the survey by web (526), those that completed all four rounds by CATI (416), and those that switched between modes, completing two rounds by web and two by CATI (510) for a total of 1,452 businesses. We decided to include this third group of "switchers" in our analysis to determine if they differ from one or both of the unimode groups. However, we excluded from the switchers group those businesses that completed three rounds by the same mode and one round by the alternative mode, regardless of order. We concluded that, for those who completed the baseline survey by CATI and the subsequent follow-up surveys by web, the change was likely related to the initial contact attempt in the follow-ups (email) rather than mode preference. We believe they likely would have completed the initial interview by web had we been able to email them at the time of the baseline survey.
Therefore, in an effort not to skew the results, we chose to exclude such cases from our analysis.

It is important to note that this is not a modal study. Self-selection of mode is a limiting factor of this analysis. Differences may be related to our ability to locate responding businesses or the businesses' eagerness to respond rather than to true modal differences.

\section{Results}

\subsection{Analysis of Business and Respondent Characteristics by Mode Choice}

We examined whether any mode effects can be detected and whether businesses that consistently chose web differ in systematic ways from those that consistently chose CATI, or those that completed in both modes. The measures we examined included business size, industry type, business complexity, productivity, and the demographic characteristics of the respondent. For this analysis, we used data collected from the most recent Third Follow-Up survey. The estimates presented are weighted and the results of chi-square tests of independence for these three groups (web-only, CATI-only, and switchers) are presented as well.

\subsubsection{Business Size}

We analyzed business size across the three groups by examining the number of employees the business had, total amount of assets held by the business, and total amount of revenue reported at the time of the Third Follow-Up Survey. Categorical groupings of the dependent variables were created for the chi-square tests. Differences were found only for businesses with employees versus businesses without employees. Businesses without employees were more likely to complete by CATI than by web. We found no significant differences between the groups in terms of assets or revenue. Results are shown in Table 2. 
Table 2. Businesses Without Employees Are More Likely to Respond by CATI (Row Percentages)

\begin{tabular}{|c|c|c|c|}
\hline & Web & CATI & Switchers \\
\hline \multicolumn{4}{|l|}{ No. of Employees } \\
\hline 0 & 28 & $37^{*}$ & 35 \\
\hline $1-2$ & 38 & 27 & 35 \\
\hline $3+$ & 38 & 31 & 31 \\
\hline \multicolumn{4}{|l|}{ Total Assets } \\
\hline$<\$ 15,000$ & 36 & 33 & 31 \\
\hline $\begin{array}{l}\$ 15,000- \\
\$ 90,000\end{array}$ & 32 & 32 & 36 \\
\hline$>\$ 90,000$ & 32 & 33 & 35 \\
\hline \multicolumn{4}{|l|}{ Total Revenue } \\
\hline$\$ 0$ & 34 & 28 & 39 \\
\hline$\$ 1-\$ 40,000$ & 35 & 31 & 34 \\
\hline$>\$ 40,000$ & 33 & 35 & 32 \\
\hline$n=$ & 525 & 416 & 510 \\
\hline
\end{tabular}

One may cautiously conclude from these results that there are no mode effects with collecting proprietary financial data, which is sometimes a concern with surveys of this population. Because no differences were found across the groups on these measures, one can assume that, overall, businesses are not under- or over-reporting these amounts on any large scale as a result of the particular mode in which the survey was completed.

\subsubsection{Business Complexity}

Business complexity was analyzed by examining the type of location in which the business operates, the legal status of the business, and the average amount of intellectual property (IP) the business owned as of the Third Follow-Up Survey. We wanted to examine, for example, whether businesses that are sole proprietorships, operate out of a home or garage, or own less IP are more likely to complete a survey by either web or CATI than more multifaceted businesses such as corporations, those that operate from a leased or purchased space, or those that own more IP. For these measures, no differences were found across the three mode choice groups. The results are shown in Table 3.
Table 3. No Difference in Complexity of Businesses by Mode of Response (Row Percentages)

\begin{tabular}{lccc}
\hline & Web & CATI & Switchers \\
\hline Business Location & 34 & 34 & 32 \\
$\quad$ Home-based & 33 & 30 & 37 \\
$\quad$ Rented/leased space & 25 & 40 & 35 \\
$\quad$ Purchased & 39 & 30 & 31 \\
$\quad$ At client location & & & \\
Legal Status & 32 & 37 & 31 \\
$\quad$ Sole Proprietorship & 35 & 29 & 36 \\
$\quad$ LLC & 35 & 28 & 37 \\
$\quad$ S-Corporation & 38 & 38 & 24 \\
$\quad$ Corporation & & & 35 \\
$\quad$ General or & & & \\
$\quad$ Limited Partnership & 24 & & 3.9 \\
Intellectual Property & & 1.0 & $\mathbf{5 1 0}$ \\
Mean & $\mathbf{5 2 5}$ & $\mathbf{4 1 6}$ & \\
\hline $\mathbf{n}=$ &
\end{tabular}

\subsubsection{Industry Type}

We examined whether businesses among the three groups differed by type of industry. A business's primary industry was categorized using the North American Industry Classification System (NAICS). The top five categories with the highest incidence were examined. Few differences were found in this analysis, as displayed in Table 4. Results show that businesses in the construction industry were significantly more likely to complete the survey by phone than by web or to switch between modes. Also, businesses in a professional, scientific, and technical services industry were more likely to complete by web than by CATI. These results are not all that surprising, as businesses in construction industries may be less accessible by email, our first mode of contact for the follow-up surveys. Businesses in professional and technical services industries, in contrast, may be more dependent on web services, making them more likely to choose web as their mode of completion. 
Table 4. Construction Businesses Prefer Telephone

While Professional, Scientific, and Technical

Services Businesses Respond via Web (Row Percentages)

\begin{tabular}{llll}
\hline & Web & CATI & Switchers \\
\hline Industry & & & \\
$\quad$ Construction & 29 & $50^{*}$ & 21 \\
$\quad$ Manufacturing & 35 & 29 & 37 \\
$\quad$ Retail Trade & 28 & 34 & 39 \\
$\quad \begin{array}{l}\text { Professional, } \\
\quad \text { Scientific, \& }\end{array}$ & $42 *$ & 24 & 34 \\
$\quad \begin{array}{l}\text { Technical } \\
\text { Services }\end{array}$ & & & \\
$\quad$ Other Services & & & \\
$\quad$ (except Public & 25 & 39 & 37 \\
$\quad$ Administration) & & $\mathbf{4 1 6}$ & $\mathbf{5 1 0}$ \\
\hline $\mathbf{N}=$ & $\mathbf{5 2 5}$ & &
\end{tabular}

\subsubsection{Profitability}

There were no differences among the web, CATI, and switchers groups when we examined the businesses' profitability in relation to mode choice. In terms of mode effects, results can be interpreted in the same way as those for total assets and total revenue discussed earlier. Like assets and revenue, a business's profit or loss information is usually regarded as proprietary information that can result in differences in reporting due to mode effects. Our analysis shows, however, that there are no differences in the data by businesses in the three mode groups. Results are presented in Table 5.

Table 5. No Differences in Profitability by Mode of Response (Row Percentages)

\begin{tabular}{lrrc}
\hline & Web & CATI & Switchers \\
\hline Profit & & & \\
Loss or broke even & 33 & 32 & 35 \\
Profit less than 20,000 & 33 & 33 & 34 \\
Profit more than 20,000 & 24 & 49 & 27 \\
\hline $\mathbf{N}=$ & $\mathbf{5 2 5}$ & $\mathbf{4 1 6}$ & $\mathbf{5 1 0}$ \\
\hline
\end{tabular}

\subsubsection{Respondent Demographics}

In addition to the business characteristics just discussed, we examined whether the demographic characteristics of the survey respondent differed among the three groups. We found no significant differences related to the gender of the respondent. However, there were statistical differences related to education levels (Table 6). Business owners who chose to complete by phone were more likely to have an associate's degree or less. In contrast, those completing by web were more likely to have a bachelor's degree or higher. This is consistent with studies of household data collection, which show that households with college degrees or higher are nearly 16 times as likely to have home internet access (Couper 2000). Although this is an establishment survey, many of the businesses operate out of a home or garage (52 percent). Respondents who chose to complete by phone were also more likely to be older than those who switched between modes. This is also consistent with findings in studies of household surveys.

Table 6. Comparison by Demographic Characteristics of Respondent (Row Percentages)

\begin{tabular}{lccc}
\hline & Web & CATI & Switchers \\
\hline Age & & & \\
$\quad 18-34$ & 33 & 30 & 37 \\
$35-54$ & 33 & 31 & 36 \\
$\quad 55+$ & 35 & $40^{*}$ & 26 \\
$\begin{array}{l}\text { Gender } \\
\quad \text { Female }\end{array}$ & 33 & 29 & 38 \\
$\quad$ Male & 34 & 34 & 32 \\
Education & & & \\
$\quad$ BA or higher & $41^{*}$ & 23 & 36 \\
$\quad$ AA or lower & 26 & $42^{*}$ & 32 \\
\hline $\mathbf{N}=$ & $\mathbf{5 2 5}$ & $\mathbf{4 1 6}$ & $\mathbf{5 1 0}$ \\
\hline * p-value $<.05$ & & &
\end{tabular}

\subsection{Analysis of Businesses' Growth Trends by Mode Choice}

Using data from all four years of the KFS, we compared the indicators of business growth across the three groups. We examined the number of employees, total assets, total revenue, and total profit. Because these are new businesses that have been operating for 
four years, we would expect some level of growth. We found few differences in this analysis.

\subsubsection{Number of Employees}

Based on the mean number of employees, the three mode groups had similar growth trends. Businesses that complete by web start out higher-with more employees than the other two groups-which is consistent with what we found earlier about employment. But, overall, they move upward on a similar trajectory, as displayed in Figure 1.

\section{Figure 1. Employment Growth Trend Similar} Across the Three Groups

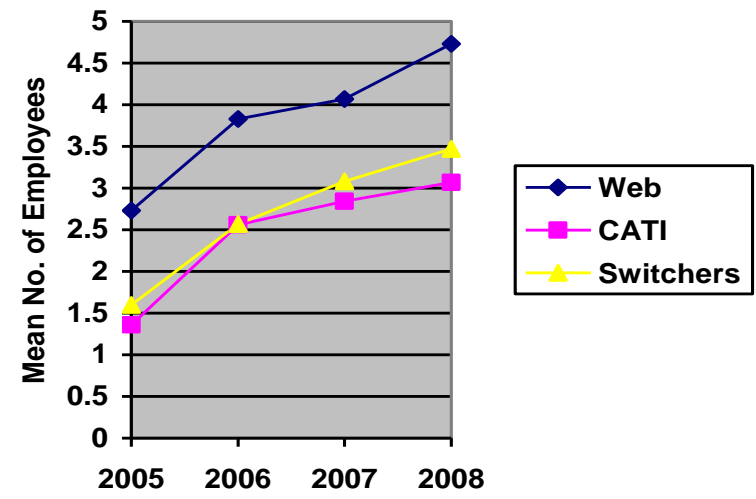

\subsubsection{Assets}

We found differences in the growth trends of assets the businesses own, based on mode choice. Businesses that completed the survey by CATI show a different trend than the businesses that used the web and those that switched modes. The CATI businesses show a peak in 2007 and then a decline in 2008, whereas the other two groups show a slight upward trend. In the context of the percentage of businesses in construction industries, it follows that as these businesses develop, they acquire more assets such as equipment and vehicles. Results are presented in Figure 2.
Figure 2. CATI Businesses Show Different Growth Trend in Assets Compared to Web and Switchers Groups

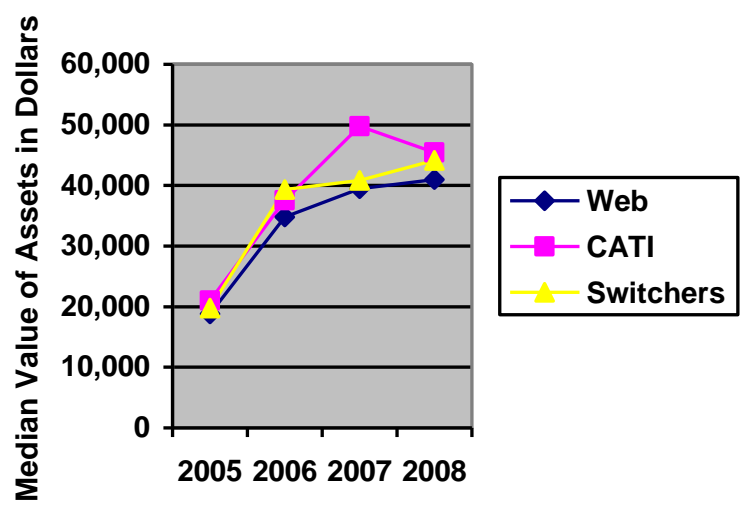

\subsubsection{Revenue}

In terms of revenue, the three groups started at similar levels, as shown in Figure 3. While the web and switchers groups show similar trends, the CATI businesses show volatility.

\section{Figure 3. Similar Revenue Trends for Web and Switchers Groups, but Different Trend for CATI Group}

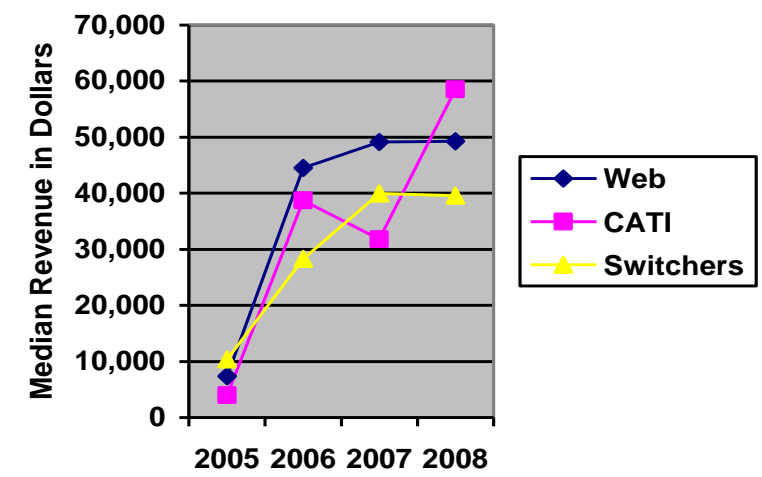

\subsubsection{Profit}

The profit growth trends for the web, CATI, and switchers groups are similar. Although they start at slightly different places, the trajectory shows a similar pattern. 
Figure 4. Profit Growth Trends Similar For Web, CATI, and Switchers Groups.

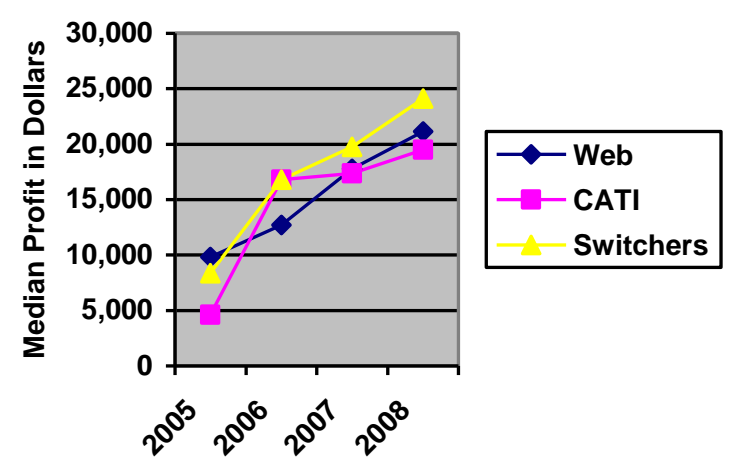

\section{Discussion}

Multi-mode methodologies are becoming increasingly popular for establishment surveys as a tool to increase response rates. To reduce costs as well as respondent burden, a web option is usually included in these mixed-mode surveys. Using data from the KFS longitudinal data set, our research seeks to discover if businesses that consistently choose web as their mode of completion differ in systematic ways from those that consistently choose CATI, and if those that switch between modes also differ when compared to those that clearly prefer one mode over the other. Our analysis found that businesses that preferred CATI were less likely to have employees and more likely to be in the construction industry, and that the respondents tended to be older and less educated than respondents in the web and switchers groups. Businesses that chose web across all years were more likely to be in a professional, scientific, and technical services industry, and these respondents tended to be more educated. There were no significant differences with the switchers group. Results seem to indicate that there are clear preferences in mode choice in terms of education level of the respondent and within some industries. Surveys should attempt to design materials that invite participation with these results in mind.

As the internet becomes more widely used as a tool for data collection, concerns over whether this mode will affect data quality have surfaced. In a mixed-mode survey such as the KFS, there may be concerns about whether responses will differ between the two modes due to differences in how the data are collected. Some research shows that when collecting sensitive data the "interviewer effect" results in differences in estimates collected between CATI and web (Manfreda 2002).
Other concerns involve how the data are entered (by the respondent rather than by an interviewer). Our analysis, however, did not detect any differences in these variables. Specifically, there were no significant differences found in total assets, total revenue, and profit between businesses that completed by web and those that completed by CATI. There were also few differences in the growth trends across the different modes. We can conclude from this that financial data collected from web participants can be comparable to those collected from phone respondents.

Because the self-selection of mode was a limiting factor of this analysis, possible future research may include a modal experiment. Future research should also look further at the impact of the mode of data collection on the respondents' substantive answers and on the quality of the data. In addition, future studies should look at the elapsed time between the invitation and the response to see if the few differences were due to propensity to respond rather than to mode.

\section{Acknowledgments}

The authors would like to acknowledge the support of the Ewing Marion Kauffman Foundation, the sponsor of the KFS, with a special thanks to E.J. Reedy and Alicia Robb. The authors would also like to acknowledge Yuhong Zheng, Zhanyun Zhao, and Giuseppe Scaturro of Mathematica Policy Research, Inc., for the statistical support they provided for this paper.

\section{References}

Couper, Mick P. "Web Surveys: A Review of Issues and Approaches." Public Opinion Quarterly, 64, 2000, pp. 464-494.

Dillman, D. A., and J. Tarnai. "Administrative Issues in Mixed-Mode Surveys." In R. Groves, P. Biemer, L. Lyberg, J. Massey, W. Nicholls II and J. Wakesberg (eds.), Telephone Survey Methodology. New York: Wiley 1988.

Manfreda, Katja L., and Vasja Vehovar. "Mode Effect in Web Surveys." Presented at the 57th Annual American Association for Public Opinion Research Conference, 2002, St. Pete Beach, FL.

Schaefer, D. R., and D.A. Dillman. "Development of Standard Email Methodology; Results of an Experiment." Public Opinion Quarterly, 62, 1998, pp. 378-397. 
Tarnai, John, and Chris Paxson. "Survey Mode Preferences of Business Respondents." Presented at the American Association for Public Opinion Research 2004 Annual Meeting, Phoenix, AZ.

Willimack, D.K., E. Nicholas, and S. Sudman. "Understanding Unit and Item Nonresponse in Business Surveys.” In R. M. Groves, et al. (eds.) Survey Nonresponse. New York: Wiley, 2002. 